Communications in Computer and Information Science, 1, Volume 19, The Open Knowledge Society. A Computer Science and Information Systems Manifesto, Pages 618-623.

DOI: $10.1007 / 978-3-540-87783-7+79$

http://springerlink.com/

http://springerlink.com/content/gn833723r9435484/fulltext.pdf

The final publication is available at www.springerlink.com.

(C) Springer-Verlag Berlin Heidelberg 2008

\title{
Framing Knowledge: Global Youth Culture as Knowledge Society (Research in Progress)
}

\section{Maureen H. Donovan}

\begin{abstract}
Widespread distribution of Japanese comics (manga) is part of a global youth culture that can be viewed as a knowledge society. The paper presents research in progress about how knowledge is being "framed" by young people through established forms or structures, through discipline associated with active learning and participation, and through thoughtful reflection and discussion with peers. Historical and qualitative methodologies are emphasized.
\end{abstract}

\section{Introduction}

Changes in creating, accessing, and using information happen within a global context and are driving forces in societies around the world. An emerging "commons" of globally distributed information and knowledge is having an impact on the work and leisure activities of people everywhere. Although information and communication technologies (ICTs) are implemented in different societies in varying ways, and significant "divides" affect individuals' and societies' access to technology and information, some widespread trends are emerging that seem "new." One of them has been the development of a global youth culture. What is different about today's global youth culture? Can studying global youth culture help us to understand broader topics, such as: how individuals navigate in the increasing (over)abundance of information, relationships among producers and users in the Knowledge Society, transborder flows of information and knowledge, the parts various stakeholders play in the production, dissemination, and management of information in the Knowledge Society?

As Japanese Studies Librarian, I collect resources in Japanese and other languages for the Ohio State University Libraries to support teaching, learning, research and service related to Japan at the university. Supporting the activities of Ohio State's Cartoon Research Library, I have been collecting Japanese cartoons and comics (manga and anime) over the past 25 years, as I watched their popularity develop from the obsession of a fringe subculture to the underpinnings of a global youth culture. Gradually some specific questions began to interest me, including:

- What can analysis of the spread of interest in Japanese manga and anime around the world tell us about changing meanings of culture in the Knowledge Society?

- To what extent does communication in popular culture domains mirror and/or differ from trends in academic/scientific communication in today's interconnected world?

- What is it about manga and anime, as well as other artistic or cultural forms emerging from Japanese culture (martial arts, bonsai gardening, haiku poetry composition, etc), that makes them so attractive in a global context? 
- Although apparently a fan-driven phenomenon, to what extent is this growing popularity pushed by commercial publishers that control intellectual property rights? How does commodification of culture facilitate/impede accessibility?

- What is the relation of global youth culture to local culture? How do local cultures fare within the context of a globalized Knowledge Society? How widely has global youth culture spread? Are there "divides" that exclude some youth from participation/awareness of global youth culture?

These and other related questions have interested me now for several years, as I struggle to identify appropriate methodologies with which to pursue them. Three years ago I began teaching a 1-credit freshman seminar, "Analyzing the Appeal of Manga," primarily as a way of immersing myself in this and getting closer to understanding what drives undergraduates who have a passion for manga. As I have been teaching this course the broad range of interconnected issues, trends, theories, and empirical concerns related to those questions is gradually becoming clearer to me and I am increasingly convinced of its relevance to wider issues regarding the Knowledge Society.

This paper presents initial ideas about my plans to proceed with this research. Although the research is still at an exploratory stage, I am developing working hypotheses that: 1) Young people are attracted, at least in part, to the discipline associated with established forms or structures (manga, martial arts, haiku, etc) when they choose to participate in global youth society. 2) Active learning and participation through training or copying is another commonality, closely related to the social networking through which discovery and access take place. 3) Contrary to what might be portrayed in mainstream media, at least some young people find opportunities for thoughtful reflection and discussion with peers of broad issues confronting society through engagement in this global youth culture. These three aspects of my working hypothesis amount to a kind of "framing" of knowledge on the part of young people, so I have chosen to use that term to describe this project, especially since it helps me to focus my attention within this complex subject.

\section{Progress Thus Far}

My early research was related to the nature of manga itself, including its genres and other characteristics and was primarily related to my activities at the library. [1].

In 2006 in a paper I presented at the International Congress on Asian Digital Libraries I began exploring broader issues, specifically related to access resources, often created by fans and/or scholars themselves, which assist in identifying and using manga and anime. My conclusion to that paper includes the following statement that reflects my awareness of this is as a user-driven phenomenon with interesting characteristics:

".... although copyright restrictions appear to have created insurmountable impediments to digital library growth for manga studies, neither fans nor scholars have been deterred by the limitations and have constructed useful access resources even in the absence of true digital libraries. The trend to make fee-based access to online manga available is emerging with a robust support structure already in place that will continue to facilitate access." [2].

\section{Theoretical Background}

\subsection{Framing Knowledge through Established Forms or Structures}

Selective investigation of key works on the forms of Japanese art and literature is essential 
to this project. Eiko Ikegami's Bonds of Civility: Aesthetic Networks and the Political Origins of Japanese Culture [3] is particularly relevant, since its focus is on how aesthetic patterns of socializing and the use of particular aesthetic forms became intertwined with political and associational life in pre-modern Japan. Other works on Japanese literary forms, such as Alexander Allard's study of bunraku [4], are also relevant, especially those related to the spread of those art forms abroad, such as Earl Miner's classic study of literary inter-relations between Japanese, French and English literature in the nineteenth and early twentieth centuries [5].

Characteristics of comics as a medium. A great amount of research is currently underway regarding "graphic novels," as manga are known in the United States to distinguish them from comics which are meant primarily for children. [6] In my teaching I use Scott McCloud's work, which draws attention to how this communication form engages readers, specifically through: iconic characters with whom a reader can identify, environments that pull the reader in, creation of a sense of refuge and silence by using successive panels to survey a whole scene, subjective motion, real world anchors, use of archetypes, and, especially, through sophisticated storytelling focused on issues of universal concern. [7] [8]

Relation to postmodern art. Postmodern approaches in art, architecture and literature arose as reactions to established modernist forms, which themselves arose in subversion to earlier styles. Recent studies of the Dada and Futurist movements (global) [9] and the MAVO movement (Japan) provide context for understanding the emergence of manga as a global phenomenon. [10]

\subsection{Framing Knowledge through Discipline Associated with Active Learning and Participation}

Reading manga requires an active participation on the part of the reader since parts of the story are omitted between the panels. Fans construct their own "story arcs" about what happened "behind the scenes." Many manga readers go further and compose their own manga, either as online comics or for sale/distribution through comic conventions. In Japan these are huge events where publishers scout out promising talent for future publication, while the vast majority of participants simply enjoy the opportunity to share their work with other fans. Increasingly this kind of sharing happens online as well.

There is a growing literature about the participatory aspects of global youth culture, especially in anthropology. A "do-it-yourself (DIY) movement is associated with the spread of manga and anime as reflected at anime conventions and elsewhere, including within the world of fashion. A growing literature on social networking is relevant in this context. In particular, I am interested in the process of resource discovery through social networks and Web 2.0 recommender systems of various kinds (commercially developed; fan/researcher developed).

In this regard I am also exploring the related topic of sports, globalization, and the role of the media in the consumption and delivery of sport, especially martial arts. [11]

\subsection{Framing Knowledge through Thoughtful Reflection and Discussion with Peers}

Gabriel Zaid reminds us in So Many Books that writing a book is a form of communication between an author and an audience. [12] Zaid notes that these days the number of books being written is increasing faster than the number of readers. At the same time he reminds us that to write a book is to open up a conversation with readers and to provide an opportunity for readers to gather and discuss the book as well. This is very descriptive of what is happening in global youth society. 
David M. Levy's research on the lack of time for thoughtful reflection and contemplation in today's "more-faster-better" society is also relevant. [13] Drawing attention to earlier research of Josef Pieper on the practice of "leisure" as essential to culture, Levy points to the central importance of the expression of the human spirit, and "of an openness to the world, to things as they are, rather than as we wish them to be." [14]

One hypothesis that I have developed is that manga are a kind of refuge for young people in today's accelerated lifestyle. Scott McCloud identifies "the sense of reader participation, a feeling of being part of the story, rather than simply observing from afar" [15] as the quality of manga that fuels its global success. Often there is a crystallizing moment in a manga that captures the essence of a feeling or experience which stands out in the storyline and provides a focus of attention and reflection, an opportunity for readers to reflect in a kind of meditative way on "things as they are." Of course, young people are also attracted to sex, action, and violence found in manga, but my work with undergraduate students over the past three years has shown me that it would be simplistic to see these popular culture materials only in that light.

\section{Methodological Outline}

Research conducted thus far has been exploratory and I am still deciding on the most appropriate methodologies to pursue. Emphasis will be on historical and qualitative research methods.

\subsection{Historical Research}

I am conducting historical research on manga as books with the aim of understanding what aspects have led to their success in Japan and catapulted them onto the world stage. This study uses research resources in Ohio State's Cartoon Research Library and explores what Pierre Bourdieu described as "power relationships in the field of production." [16] Current research focuses on 1) the evolution of guides to manga over the decades in Japan and new guides developed specifically for a global context, and 2) manga instruction manuals and the evolution of technical terminologies, as well as how those have changed in transnational settings.

\subsection{Ethnographical Study}

I am preparing to conduct a study of manga fans among Ohio State University students and local anime convention participants. American college students who read manga will be the focus of planned interviews aimed at refining the hypotheses outlined above. Do the three aspects show up when students are interviewed about how they read manga or do I need to revise them? This part of the study can be seen as dealing with the reception and acclimatization of manga within an American context. Depending on how it goes, I may want to replicate it in other contexts, perhaps with cooperation of researchers elsewhere. I will use techniques of focused ethnography for this aspect of the study. In designing my study I have been influenced by user studies conducted by Susan Gibbons and Nancy Fried Foster as part of the Extensible Catalog project at the University of Rochester. [17][18]

\subsection{Action Research}


As a librarian I am interested in supporting people in their information life. Therefore I am also drawn to use what is called "action research" (AR) for another aspect of this study. My reason for choosing AR as a methodology is that I have a hunch, articulated above, that some aspects of the "framing" that take pace within global youth society can be extended beyond that context and may have wider application beyond the social networking of youth. As a starting point, I plan to include the following in forming a critical reference group of people who would participate in the research and benefit from its results. This are likely to include non-participants in global youth culture (among young people), representatives of their parents' generation, people who feel overwhelmed with information over-abundance, people who shake their heads at a youth's absorption in global youth culture and so on. The "action" that I will seek as a follow up to this research is related to improving their information lives.

\subsection{Content Analysis}

Another approach that I am taking is analysis of writings about global youth culture, manga, etc in blogs and other online sources as well as publications in print. To what extent do young people have self-awareness of their participation in a global youth culture and what do they say about it themselves? Is there validation of my hypotheses in their writings? Also, I am collecting publication and circulation data regarding the global distribution of manga.

\section{References}

1. Donovan, M.H.: Problems and Perspectives from a University Library Manga Collection. Manga Kenkyu 6, 156-165 (2004) (in Japanese)

2. Donovan, M.H.: Accessing Japanese Digital Libraries: Three Case Studies. In: Sugimoto, S., Hunter, J., Rauber, A., Morishima, A. (eds.) ICADL 2006. LNCS, vol. 4312, pp. 410-418. Springer, Heidelberg (2006)

3. Ikegami, E.: Bonds of Civility: Aesthetic Networks and the Political Origins of Japanese Culture. Cambridge University Press, Cambridge (2005)

4. Alland, A.: The Construction of Reality and Unreality in Japanese Theatre. The Drama Review 23(2), 3-10(1979)

5. Miner, E.: The Japanese Tradition in British and American Literature. Princeton UP, Princeton (1966)

6. Comics research bibliography, http: //www. rpi . edu/-bulloj /comxbib.html

7. McCloud, S.: Understanding Comics. Harper, New York (1994)

8. McCloud, S.: Making comics. Harper, New York (2006)

9. Dickerman, L.: The Dada Seminars. Library of Congress, Washington (2005)

10. Weisenfeld, G.: Mavo. University of California Press, Berkeley (2002)

11. Jarvie, G.: Sport, Culture and Society. Routledge, New York (2006)

12. Zaid, G.: So Many Books. Paul Dry Books, Philadelphia (2003)

13. Levy, D.M.: No Time to Think: Reflections on Information Technology and Contemplative Scholarship. Ethics and Information Technology 9, 237-249 (2007)

14. Pieper, J.: Leisure: The Basis of Culture. Faber, London (1952)

15. McCloud, S.: Making comics. Harper, New York (2006)

16. Bourdieu, P.: The Field of Cultural Production. Polity, Cambridge (1993)

17. Foster, N.F., Gibbons, S.: Studying Students: The Undergraduate Research Project at the University of Rochester. ACRL, Chicago (2007)

18. Extensible Catalog, http: //www. extensiblecatalog. info/ 